\title{
Três Congressos Mundiais de Tribunais de Contas
}

Entrevista concedida à R. S. P. pelo Ministro Pereira Lira (Presidente do 3․ Congresso; e Presidente do Tribunal de Contas da Uniãc).

DE QUE SE TRATA

A guisa de entrevista, são ditadas estas considerações, com enderêço à Revista do Serviço Público, e destinadas a dar aos leitores não especializados uma visão, ainda que muito rápida, dos memoráveis conclaves, reunidos em Havana (1\%), Bruxelas (2) e Rio de Janeiro (3\%).

Êste último ocorreu entre 4 e 9 de maio de 1959, por convocação do nosso Tribunal de Contas da União e sob o alto patrocínio do Poder Executivo, da Câmara dos Deputados e do Senado Federal, da República Brasileira.

Os dois primeiros tiveram lugar, respectivamente, em Havana, 1953; e em Bruxelas, 1956.

Quiz a Revista do Serviço Público, de tanto relêvo e autoridade entre nós, dedicar a presente edição ao último dêsses certames, tão bem sucedido, e cujo nome oficial é o de " 3 " Congresso Internacional das Instituições Superiores de Contrôle das Finanças Públicas".

A Presidência do " 3 ? Congresso" e támbém do Tribunal de Contas da Uniãn foi solicitada a concorrer, em entrevista exclusiva, com um roteiro histórico, para servir de preâmbulo à primeira documentação do " 3 " Congresso" que será recolhida nas páginas desta publicação, recenseando as resoluções e fixando as recomendações, não só do último, mas também dos dois magnos conclaves anteriores.

Não se trata, ainda, de sublinhar as conseqüências a extrair das lições cotejadas nessa troca mundial de experiências, adquiridas no concêrto das nações civilizadas, nem de proceder à verificação das possiveis repercussões no plano nacional, como no internacional.

$\mathrm{E}^{\prime}$ mais modesta, aqui, a meta a que se visa.

Quando publicados os "Anais do $3^{\circ}$ Congresso", - só então soará a hora da análise, da crítica, da apuração de resultados. 


\section{CONGRESSOS - INSTRUMENTOS DE CULTURA}

Não cabe, nesta assentada, insistir em que os "Congressos" dos especialistas e os "Encontros" dos técnicos representam o melhor incentivo ao enriquecimento, cada vez maior, do patrimônio da Cultura e à ascensão constante de níveis dos progressos humanos.

Hoje, a educação se continua na idade da madureza, na plenitude do espírito, se é que não se vitaliza especialmente nela, pois que já o treinamento dos joveus é feito para a Vida e "dentro da Vida".

Por outro lado, a rigor, o verdadeiro e eficiente processo de aquisição de conhecimento é o "processo co-educativo".

Cada campo profissional é uma espécie de "clearing-house", para a conunicação recíproca de dados, conseguidos experimentalmente e incorporados ao acervo cotilum, no seio de cada povo.

Isso ocorre no tempo, e no espaço, projetando-se além das áreas internas, para ambicionar padrões universais.

Uina geraçào sobe nos ombros das outras.

Uma nação inspira-se nas conquistas das demais, tendo-as sempre presentes.

Um grupo social aproveita, internamente, das tentativas e erros dos grupos vizinhos, que são todos, pois que o Mundo é, implacàvelmente, um Mundo só.

$\mathrm{E}$ isto é feito, consciente ou inconscientemente, através do processo intuitivo da "educação recíproca".

$\mathrm{Na}$ pedagogia dos jovens, como na disciplina de comportamento dos adultos, não há mais que falar em "instrução" ou "educação", mas, já agora, em "co-instrução" e em "co-educação".

E' êstc, por isso, o quartel de século das "conferências", principalmente se nos debruçarmos na semântica e na etimologia dessa palavra mágica que tomou conta das atividades intelectuais, com o seu séquito analógico de "congressos", "encontros", "seminários", "colóquios", "simpósios" e "mesas -redondas".

Mostram as estatisticas que há um "congresso" por dia, em cada uma das grandes cidades, ou naquelas que, sem ser grandes, oferecem condições de receptividade material, para tão fecundas reuniões.

\section{DEMOCRACIA E CONTRÔLE}

Os que têm como profissão realizar a fiscalização superior das "contas públicas", - êstes, também, não fugiram ao espirito dominante, nesta "volta" de século.

Através do estudo do direito comparado, sempre se beneficiaram, vivamente, do que os povos têm realizado dentro do tema atualissimo e inevitável da execução do contrôle da administração financeira. 
Iniciativas privadas nas trocas de informações e o esfôrço de alguns abnegados, como Salvatore Sica, - a contribuição da doutrina, - as revistas técnicas, - os institutos de direito público, - a obra bem inspirada da U.N.E.S.C.O., - tudo vem congregando os "homens do ofício", pondo em contatc os comparatistas da "especialidade", e, aproximando, além dos indivíduos, todo o grupo institucional do que, aqui, se chama "Tribunal de Contas", ali, "Cour des Comptes", e, mais adiante, "General Comptroller" ou "Contraloria General".

Percebem-se os primeiros sinais de uma tendência de uniformização das politicas nacionais de fiscalização técnico-financeira, e, ùltimamente, começa a formar -se uma consciência da necessidade dessa mesma fiscalização, em nivel superior, sôbre os organismos internacionais e supranacionais.

Os controladores superiores das finanças públicas, sejam os instituidos em feição de colegialidade, sejam os de forma unipessoal, - uns e outros se defrontaram, mais uma vez, em face da Esfinge de todos os tempos, e estão compelidos a pleitear o aperfeiçoamento dos mecanismos de coleta e aplicação dos recursos públicos, retirados dos contribuintes, e, ainda, a encarecer a estruturação de aparelhos de vigilância e contraste sôbre instituições, ora situadas fora dos quadros nacionais.

Alguns dêsses problemas, derivados da vida financeira do Estado, e velhos como as civilizações mesopotâmicas, reviveram, com intensidade, na Era da democracia restaurada, após o derradeiro conflito universal.

A respeito, tive ocasião de escrever no "Boletim" n? 1 , do "3? Congresso":

"O aperfeiçoamento das técnicas de fiscalização financeira corresponde a um imperativo do florescimento das instituições livres.

"Já se disse, com sabedoria, que, se é dificil definir, por forma positiva, a democracia, - muito fácil se torna dizer onde ela não viceja nem existe.

"I. um dos testes para ter uma organização politica como incluída, ou não, na área das Dzmocracias, é indagar se há efetiva vigilância, por parte do Povo, acêrca da coleta e aplicação das contribuições que êste presta ao Tesouro Público, e se essa vigilância se exerce através de adequados e eficientes órgãos de contrôle, de livre funcionamento, com execução assegurada efetivamente para as suas deliberações.

"A contribuição que, pessoalmente, oferecemos ao 1? Congresso (de Havana) foi um depoimento da experiência brasileira e a formulação de uma lei sociológica: o maior alcance da fiscalização preventiva, na execução dos orçamentos do Estado, está na razão direta do maior progresso das instituições e práticas democráticas, e na razão inversa da intensidade dos surtos ditatoriais, ostensivos ou larvados". 
"No ano passado, por ocasião das comemorações do sesquicentenário da Cour des Comptes, em Paris, no Palácio Cambon, ouvimos através da palavra do Sr. Raul Reynaud, Presidente da Comissão de Finanças da Assembléia Francesa, a confirmação de que, ali, aquêle órgão do Estado tem gozado de maiores podêres, sempre que foram maiores as liberdades públicas.

" $E$ ' essa, pois, a lição da história da Instituição, aquém e além-mar, na América, como na Europa.

"Incentivar e realizar Congressos como êste, desenvolvendo relações internacionais entre altas Entidades Fiscalizadoras do Mundo, é, seguramente, servir à Democracia".

\section{O CONGRESSO DE HAVANA}

\section{(1 Congresso Internacional - 1953)}

Coube a um eminente Professor da Universidade de Havana e, então, Presidente do Tribunal de Contas da República de Cuba, o Doutor Emílio Fernandez Camus - exprimir, com anterioridade, o anseio dos juízes e controladores de contas públicas, em todo o Mundo.

A êle prestei homenagem merecida, no discurso de abertura do " 3 " Congresso", solenemente instalado pelo Senhor Presidente da República, comı a presença do Senhor Presidente da Câmara dos Deputados, do Corpo Diplomático e dignitários da República Brasileira, no Palácio Tiradentes, em 4 de maio de 1959, nas seguintes palavras:

"Quando o Presidente do Tribunal de Contas de Cuba peregrinava pela América e pela Europa, lançando a idéia dos Congressos dos Tribunais de Contas, - estávamos longe de supor que ao Brasil tocaria tão cedo a honra de agasalhar delegações, de tantas credenciais e de tanta autoridade, vindas de pontos tão variados do Planêta, de um e de outro Hemisfério".

Os trabalhos realizados em Havana, dada a vastidão do temário, desenrolarani-se com grande riqueza de sugestões, alicerçadas em contribuições notávcis. Mas o que interessa, nesta resenha, é, por sem dúvida, focalizar as conclusões que, ali, tiveram relêvo real.

Cumpre assinalar que o Brasil não estêve ausente, comparecendo com as seguintes teses a) "Os Tribunais de Contas como agentes de soberania do Povo", de autoria do antigo Auditor Dr. Ernesto Claudino de Oliveira E CRUz: l.) e "A importância da fiscalização preventiva", do entrevistado, então Vice-Presidente do Tribunal de Contas da União.

A representação do Tribunal brasileiro estêve a cargo do Ministro Silvestre Péricles de Góes Monteiro e do então Procurador Dr. Cunha Mello. 
Os pontos altos do Congresso de Havana (1\% Congresso) podem ser resurnidos, como abaixo:

A) Sôbre a independência das entidades fiscalizadoras, acordou-se em Havana:

$1^{\circ)}$ que, às entidades fiscalizadoras do maneio dos fundos e dos bens públicos, se lhes conceda indepandência jurídica $e$ institucional ante as atividades executivas que devam estar debaixo de sua intervenção;

2.) que se reconheça às entidades fiscalizadoras a faculdade de defender a manter essa independência, mediante o exercício das açōes corres pondentes, nos casos em que a mesma resulte violada ou ignorada;

3:) que o contrôle fiscal deve exercer-se com espirito isento de tôda política partidarista, e sem entravar a gestão administrativa;

4\%) que se assegurem às entidades fiscalizadoras os meios necessários, a fim de que possam cumprir, de modo completo, a missão que lhes incumbe:

$\left.5^{\circ}\right)$ quee é convariente outorgar às instituições de contrôle jurisdição para fiscalizar, tanto os fundos que são manejados através do Orçamento, como os que são administrados por maio de entidades ou estabelecimentos públices descentralizados.

B) Sôbre o Secretariado Permanente, foi resolvido em Cuba:

- estabelecer, com sede em Havana e escritórios no Tribunal de Contas de Cuba, um "Secretariado Permanente", com funções de:

a) convocar o próximo Congresso;

b) instalar Agéncia ou Representação do mesmo Secretariado de acòrdo com o país escolhido para sede do próximo Congresso;

c) realizar os estudos necessários, em consulta com as Delegações interessadas, a fim de objetivar o estavelecimento de um Conselho Internacional de Entidades Fiscalizadoras;

d) organizar em Cuba os escritórios do Secretariado, e publicar um "Boletim Informativo".

C) Sôbre o contrôle preventivo, foi decisão do Congresso de Havana:

18) recomendar a necessidade de um contrôle preventivo exercido sôbre as receitas e sôbre os gastos das Entidades Públicas:

$2^{\circ}$ ) proclamar que, sejam quais forem as modalidades de aplicação do contrôle prévio, torna-se indispensável exerçam-no funcionários públicos con pletamente independentes dos organismos sujeitos à fiscalização;

3:) declarar também que dito contrôle prévio deve completar-se com a organização de um adequado contrôle a posteriori. 
D) Sôbre a ação do contrôle prévio e a da contabilidade, foi entendido que:

- convém relacionar a ação fiscalizadora do contrôle prévio com a contabilidade, como base de preparação, para o Govêrno, de informes financeiros de estimativa que o habilitem a dirigir, com acêrto, o rumo dos negócios financeiros do Estado.

E) Sôbre as funções de assessoria das entidades fiscalizadoras, acordou-se em que:

- as Entidades Fiscalizadoras atuem como Conselhos ou Assessorias Técnicas das Assembléias ou Congressos Legislativos; e que estandam suas atribuições de intervenção preventiva a todos os atos relacionados com o Orçamiento das Entidades de Direito Público.

Essa atividade fiscalizadora, até o momento de ser apresentado o orçamento ante o Congresso, deve revestir o caráter de cooperação com o Poder Executivo no ramo encarregado da direção da Fazenda Pública, tudo isso com sujeição às disposições constitucionais, próprias de cada País .

Êste foi o resultado do "12 Congresso".

O CONGRESSO DE BRUXELAS

\section{(2. Congiesso Internacional - 1956)}

O Conclave realizado na Bélgica enfrentou, com decisão, um tema fundamental: "meios institucionais adequados à asseguração da independência dos Coripos encatregados do contrôle superior das finanças públicas".

Depois de longos e proveitosos debates, o "2. Congresso Internacional" proclamou que uma sadia gestão dos dinheiros públicos exige a existência, em cada país, de Instituição Superior de contrôle das finanças públicas, dotada de independência absoluta em face das autoridades administrativas, e protegida contra as influências estranhas à Instituição.

Para atingir êsse fim, o " 2 ? Congresso Internacional" declarou que devem scr adotados os seguintes princípios:

19) existência de Coupos de Contrôle, com sua estrutura geral e com a natureza de sua missão, devidamente fixadas na Constituição, a qual deverá estabelecar, também, a independência dêsses Institutos e a inamovibilidade dos seus membros;

$2^{\circ}$ ) lei que estabeleça as modalidades dessa independência e dessa inamovibilidade, e que fixe as condições de nomeação ou de elegibilidade, assim como determine a autoridade competente para fazer a nomeação, tendo em conta a estrutura do Estado-Nação; e as condiçōes de aposentação e tudo o mais que interesse às garantias estipuladas;

3:) previsão, na lei, dos relatórios, documentos e observações que a Instituiçào deve produzir 'e publicar; 
4:) recrutamento do pessoal administrativo pela própria Instituição, gozando tais servidores de $\mathrm{um}$ Estatuto que garanta estabilidade no emprêgo;

5:) existência de orçamento próprio, para a Instituição Superior de contrôle, por ela proposto. Se o Govêrno introduzir modificações na proposta de orçamento, apresentada pela Instituição Superior de contrôle, será obrigatório que se submeta ao Parlamento, ao mesmo tempo, a proposição original. A execução do seu orçamento caberá à própria Instituição.

No tocante a essa matéria, o nosso Tribunal de Contas levou a Bruxelas a sua contribuição, representada pela tese, de autoria do entrevistado, sôbre "as características do sistema brasileiro para assegurar a independência do Tribunal de Contas e dos membros que o compõem", estando a nossa Delegação composta pelos Senhores Ministros Silvestre Péricles de Góes Monteiro e Rogério dF Freitas.

Ontro assunto que figurou na agenda do Congresso de Bruxelas tinha por epígrafe: «meios adequados à asseguração do contrôle financeiro das instituiçōes internacionais ou supranacionais».

O Plenário partiu do principio de que a existência e a eficácia de um contrôle "externo" de tôdas as receitas e de tôdas as despesas, referentes a êsses organismos, estão incluidas em o número das condições essenciais para estabelecer a confiança que os povos dos Estados-membros devem ter no bom funcionamento das instituições internacionais ou supranacionais nas quais êles estão ínanceiramente interessados.

Teve, ainda, em mira o Plenário do " 2 " Congresso" que êsse contrôle financeiro sôbre instituições internacionais ou supranacionais, se é sempre idêntico em seus fins, pode e deve variar nas suas modalidades de organização, a fim de se adaptar à diversidade das estruturas, e das finalidades dessas instituições.

Por fôrça de tais premissas, com a finaìidade de, ao exercício mesmo dêsse contrôle financeiro "externo", assegurar as garantias de independência, competência e eficácia que lhe são indispensáveis, o " 2 : Congresso" recomendou:

- que seja feita, sempre, pelo conjunto dos delegados dos Estadosmembros, a nomeação dos "Comissários de contas" das instituiçŏes internacionais ou supranacionais;

-- que recaia essa nomeação em pessoas de notória e alta qualificação profissional, a ser reconhecida em face de um certo número de critérios técnicos determinados:

- que - para o contrôle das instituições, que recebem contribuições dos Estados membros - a nomeação de cada um dos "Comissários de contas", assim, reconhecidos aptos ao exercicio dessas funções, seja feita sempre depois de parecer motivado do Chefe da Instituição superior de contrôle das finanças públicas do país ao qual pertence o nomeando; 
- que, coni: vistas às instituições internacionais ou supranacionais que recebam contribuições dos Estados-membros, grupados, para êsse efeito, segundo sua implantação geográfica ou segundo a similitude de sua estrutura e de seu funcionamento —, sejam progressivamente estabelecidas uma ou várias Instituições Superiores de contrôle financeiro, de forma jurisdicional, encarregadas de apurar, eventualmente, a responsabilidade financeira dos funcionários internacionais, e de ordenar as medidas de execução adequadas a sançã eficaz: e

- que um texto de aIcance geral, a ser adotado depois da necessária investigaçân junt: das instituições interessadas, delimite, com precisão, o campo de ação do contrôle financeiro "externo", a fim de fixar claramente as competências, e deterninar as responsabilidades.

A vista de tudo isso, o " 2 ? Congresso" decidiu nomear imediatamente uma Comissão de estudos e de redação, composta de sete membros, encarregada de preparar um projeto de convenção internacional que determine: a natureza e a extensão da responsabilidade financeira dos administradores internacionais; $c 3$ contrôles aos quais sua gestão deve ser anualmente submetida; e os meios de aplicar sanção efetiva pelas responsabilidades verificadas.

Êsse projeto de convenção internacional sôbre o contrôle financeiro das instituições internacionais ou supranacionais se destinava a ser submetido à aprovação do próximo Congresso (o do Rio de Janeiro), e comunicado, em seguida, para exame e adoção eventual, às Assembléias deliberantes das Instituições internacionais ou supranacionais.

Sem esperar a celebração do " 3 ? Congresso", tal projeto poderia ser encaminhado aos Chefes das Delegações presentes ao " 2 " Congresso", aos cuiłados da "Comissão de estudos e de redação", a fim de recolher as observações e a adesão de tôdas as Delegações que participaram dos trabalhos do Congresse de Bruxelas.

- A "Comissão de Estudos e de redação" foi imediatamente nomeada.

O terceiro assunto que ocupou a atenção do Plenário do " 2 " Congresso", ou seja o Congresso de Bruxelas, foi o de encontrar "os meios adequados à asseguração do contrôle financeiro das "indústrias nacionalizadas" e dos "organismos que se beneficiam de participação financeira do Estado".

O "2? Congresso" considerou que, em razão das repercussões que a gestão dessas emprêsas e dêsses organismos pode ter sôbre as finanças públicas e sôbre a economia da Nação, um eficiente contrôle financeiro deve ser exercido, no curso da gestão e a posteriori, sôbre tais emprêsas nacionalizadas e sôbre tais organismos cujos orçamentos são alimentados com receitas parafiscais ou se benificiam de participação financeira do Estado.

Conforme o votr: do Plenário, para atingir suas finalidades, deve ser assegurado êsse contrôle, râo sòmente por órgãos especializados, mas, ainda, 
pela Instituição superior de contrôle das finanças públicas de cada país interessado.

Também se entendeu que o contrôle pela Instituição superior deve ter por objeto não sòmente a exatidão das contas, mas, igualmente, a qualidade da gestãc e a rentabilidade da emprêsa.

Mereceu ainda aprovação do "2 2 . Congresso" outra recomendação qual seja a de que, para cumprir eficazmente sua missão, essa Instituição Superior deve poder: - adotar processos adequados, e, ainda - assegurar-se o concurso de peritos "externos", - - dar diretivas, e - atilizar os contrôles especializados "externos" e internos aos quais é submetida a emprêsa.

Conciuiram as recomendações do Plenário do "2" Congresso" insistindo em que os resultados do contrôle da Instituição Superior devem ser comunicados ao organismo administrativo de tutela, assim como ao Parlamento.

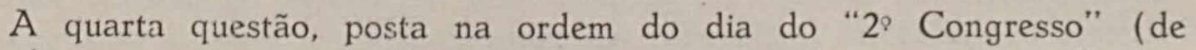
Bruxelas), reportava-se a "instituição de um contrôle preventivo sôbre as despesas públicas; seus fins e suas modalidades".

Êsse tema já surgira no "1" Congresso" (de Havana), e fôra, aliás, versado ne tese brasileira, antes referida, ao averiguar o paralelismo, no Brasil, entre os eclipses da Democracia e o consequiente desaparecimento da fiscalizaçâo preventiva.

Foi entendido pelc "2" Congresso".

- que é indispensável um contrôle preventivo, para assegurar correta execução do orçamento;

-- que o contrôle preventivo das despesas públicas pode ser exercido tanto no momento do empenho das despesas como depois, entendendo os Delegados ao "2 2 " Congresso" que o contrôle preventivo mais eficaz é o exercido ao serem empenhadas as despesas;

- que, tendo em linha de conta estruturas peculiares a cada país, deixa-se a cada um dêles, de per si, a escolha de confiar o contrôle preventivn; ou a um organismo administrativo, independente do serviço da despesa, ou à própria Instrução Superior de contrôle.

Finalmente, o "2. Congresso Internacional", reunido em Bruxelas, emitiu um voto, assinı consubstanciado:

- que seja constituido, como organismo permanente, um Conselho Internacional das İnstituições superiores de contrôle das finanças públicas;

-- que êsse "Conselho" tenha como objetivos essenciais a busca dos meios adequados à asseguração e à manutenção da autonomia dos organismos que o compõem, assin como o estudo e o desenvolvimento do direito especifico das Instituições de contrôle das finanças, nos diferentes países do Mundo;

- que, para atingir essa finalidade, o "Conselho Internacional" deve entreter relações de coopəração com as instituições internacionais, notadamente com a U.N.E.S.C.O., e com os organismos nacionais cuja atividade se refere ao mesmo objeto ou que perseguem fins idênticos; 
- que, além disso, é de recomendar venha o "Conselho Internacional" a prestar aos Governos, que os solicitem, os serviços técnicos que dependam da competência daquele e cı1ja forma e modalidade serão fixadas por um regulamento.

Êsses foram os resultados do "2" Congresso".

\section{CONGRESSO DO RIO DE JANEIRO \\ (3: Congresso Internacional - 1959)}

As notícias oficiais, amplamente divulgadas pela operosidade da Secretaria Geral do "3० Congresso", durante o curso dos trabalhos, bastam para mostrar que a honra conferida ao Tribunal de Contas dos Estados Unidos do Brasil, na organização do conclave, - teve a sua equilibrada contrapartica no esfồço, empregado pela Delegação Brasileira, para que fôssem atingidas as finalidades almejadas.

Não é éste o lugar adequado para analisar a contribuição brasileira. a que se devotaram: - o Ministro Rogério DE Freitas, como representante do Secretariado Permanente do Congresso, com sede em Havana e depois Secretário-Geral: -.. o Ministro Joaquim Henrique Coutinho, distinguido pelo Plenário com os encargos, brilhantemente desempenhados, de Relator Geral de uma das mais importantes teses ("Atribuições do Organismo Su. perior de Fiscalização no que concerne às receitas"); - o Ministro Gustavo Capanema que, no Plenário do Tribunal de Contas da União, em recepção à Delegação portuguêsa, produziu notável peça de direito administrativo comparado; -- o Procurador Cristiano Martins que, na mesma ocasião, cinzelou uma página de alto valor literário, - e o Dr. JosÉ EscolÁstico Abreli de Oliveira, de Corpo de funcionário da Casa, que logrou ver largamente apreciado trabalho de sua autoria.

Não estäo ainda publicados, mas esperados para muito breve, os "Anais do 3" Congresso": é cedc, portanto, como no principio foi dito, para empreender a análise dos seus resultados e das teses da reunião do Rio de Janeiro.

Em todo caso, é mister assinalar, desde já, a objetividade com que se conduziu o "3. Congresso", resguardando-se dentro de área de razoável prudência e não levando além do possivei as suas resoltções.

A aspiração, de longe acalentada, da criação de um Conselho Inter. nacional das instituições de contrôle das finanças públicas, - foi ela reafirmada, mais uma vez, com adesão generalizada.

Com igual repercussão contou ainda a tese do estabelecimento de contrôle finançirs sôbre as instituições internacionais e supranacionais.

Desde a instalação do " 3 ? Congresso", no Palácio Tiradentes, em 4 de maio de 1959, - como Presidente do Tribunal de Contas da União, exprimira eu o ponto-de-vista brasileiro, nestas palavras:

"Ninguém (individuo ou Estado) conseguirá subtrair-se au império da lei da gravitação recíproca". 
"Se c homem é, reconhecidamente, um animal politico, -- as Nações, por sua vez, exprimem-se como pessoas morais, com atributos e deveres humanos, sentindo e sofrendo, aspirando e sonhando".

"As alianças imediatistas do passado são substituídas por instrumentos pcrmanentes de realização das tarefas superiores da Humanidade".

"Afirmado ontem como simples tendência espiritual, - um rumo novo decanta-se hoje em aparelhos concratos e efetivos de uma política de solidariedade, com as suas consequiências no plano material e financeiro".

"Todos os membros da família humana concorrem com o produto de impostos, para organizações de caráter não nacional.

"Elas já são em número elevado, e crescente, de tipo universal cu regional, de fins econômicos ou não, abraçando continentes, ou parte dêles, cobrindo terras e mares, como: a Organizaçäo das Nações Unidas e as entidades nela incluídas para a Cultura, a Alimentação, o Trabalho ou a Saúde do Mundo; o Conselho da Europa; a Organização Européia pró-Cooperação Econômica: a União da Europa Ocidental; a Organização do Tratado do Atlântico, e a Comunidade Européia do Carvão e do Aço".

"Nas Américas, a Organização dos Estados Americanos se reveste de um corpo de feição continental a que se junta, promissoramente, nesta hora do despertar de energias latentes, a Operação Pan-Americana, iniciativa oportuna e feliz do Govêrno do Brasil".

"Nc futuro, novas organizações, notadamente de finalidades econômicas, terão de servir, no Continente, ao Brasil e aos países irmãos, para enfrentar problemas como o das comunicações terrestres da costa atlântica à costa pacífica, com os problemas amazônicos e platinos, २, ainda mais pròximamente, como o do aproveitament: da energia das Cataratas de Iguaçu, - iniciativas que estãc: na dependência, material e geográfica, da cooperação internacional".

"Na hora que passa, o orçamento brasileiro já consigna, para êsse tipo de despesas, não nacionais, mais de oitenta rubricas, o que mostra o nosso interêsse direto nos estudos e deliberações dêste "34 Congresso", em tôrno do tema referente ao Contrôle das Instituiç̃̃es Supranacionais e Internacionais".

"Assir:, fatos novos reclamam direito novo".

"O hornem-contribuinte verte fração ponderável do produto do sfu trabalho em subsidios a aplicar, dentro e fora das fronteiras de sua Pátria". 
"O nascim€nto constante de Org̣anizações Internacionais gera, com o dever de prestar as contribuições, o direito de fiscalizar o emprêgo dêsses dinheiros públicos, tanto em entidades supranacionais como internacionais, a beneficio do progresso social".

“ $E$ ' direito da cidadania, na esfera nacional, ou fora dela, votar o impôsto, regular a sua incidência e conhecer o seu emprêgo".

De tudo isso, se infere, nitidamente, que a Delegação Brasileira tinha ponto-de-vista firmado, tanto no sentido da criação de um «Conselho Internacional das instituições de contrôle das finanças públicas", como ainda no estabeiecimento de um "contrôle das instituições internacionais ou supranacionais".

Foi, contudo, prudentemente entendido que a opinião internacional ainda não estava suficientenente amadurecida para a criação de corpos que, ademais, poderiam suscitar objeções, nascidas de várias origens, inclusive da diferenciação constitutiva c funcional dos órgãos de contrôla de cada país, e da necessidade dz negociar, convencionar e pôr em funcionamento tratados internacionais, interessando podêres executivos e parlamentos de países de cinco continentes.

A grande niaioria dos Congressistas, nos entendimentos extraplenário, verificou existir, ainda, falta de preparação e receptividade para atacar, com êxito e segurança, a transformação da idéia generosa em realidade fecunda.

Manticia, no entanto, a aspiração, - forçoso era e é demandar a ação do tempo para formação de ambiente indispensável à boa, uniforme e unânime receptividade do "Conselho Internacional", para o que sa faz mister a ação de uri "Secretariado Permanente", assistido por "Grupos de Trabalho", implantados aqui e além.

Foi, assim, mantido a atual "Secretariado Permanente", a ser ajudado por cinco "Grupos de T'rabalho", um em cada Continente, ficando o "Secretariado Permanente" com a missão específica, além de outras, de estabelecer e alimentar contato com o Conselho Econômico e Social das Nações Unidas, e staas Agências especializadas.

Êsses trabalhos nâo deverão perder de intensidade durante os periodos entre a realização de un e outro Congresso das Entidades superiores de fiscalização, devendo "Secretariado Permanente" e "Grupos de Trabalho" prosseguir nos estudos e atividades, tendentes à organização do futuro "Conselho Internacional".

No tocante ao contrôle das instituições internacionais e supranacionais, - ter-se-ia e ter-se-á de lançar mão, também, de estipulações insertas em tratados, com a aprovação de numerosos Estados participantes, o que se obterá futuramente, mas à custa de sérias dificuldades e com insuperáveis demoras. 
Impôs-se ao "3? Congresso", no momento, uma declaração sincera, tornando, contudo, enfática a necessidade de contrôle externo, nos seguintes têrmos de recomendação:

19) Em cada instituição internacional, deve ser constituida, e, assim, sob forma colegiada, uma "Junta de Comissários de Contas" cujos membros devem ser escolhidos, mediante rodizio, entre os indicados pelos associados da Organização;

29) o modo de designação dos "Comissários de Contas" deve assegurar a êstes independência absoluta em relação à instituição que vão fiscalizar; com êsse propósito, é mister cada "Comissário" seja escolhido dentre os membros das Instituições Superiores de contrôle, e nomeado pelo Govêrno de cada país interessado;

3) o relatório anual da "Junta dos Comissários de Contas" salientará o aumento ou diminuição de despesas, tanto em referência ao exercício examinado, quanto em relação ao exercício anterior, fazendo consignar justificativas das alteraçôes verificadas;

48) tal relatório consignará se as observações, então já apresentadas pela "Junta dos Comissários de Contas", produziram resultados apreciáveis, e quais as sanções que foram impostas, no caso de se terem verificado irregularidades ou falhas administrativas, de natureza grave.

No tocante às atribuições das Instituições superiores de contrôle, quanto às receitas, foi recomendado pelo "3: Congresso":

19) as Instituiçiies superiores de contrôle das finanças públicas devem exercer, dentro de suas atribuições, a mais ampla fiscalização da receita;

$2^{\circ)}$ a fiscalização não se aterá à simples apuração da arrecadação da receita diante das contas apresentadas pelos exatores, mas, sempre que possivel, verificará se a entrega de tributo obedeceu à legislação;

$3^{\circ}$ ) as Instituições Superiores de contrôle devem examinar, no final do exercício, se foram atingidas as cstimativas da receita. Em caso contrário, procederăo ao necessário exame, para verificar se houve negligência na arrecadação ou exagêro na estimativa;

4) os parcceres das Côrtes de Contas sôbre a gestão orçamentária, dirigidos aos Parlamentos, devem conter o máximo de esclarecimentos no tocante à receita, tal como se procede em relação à despesa;

$\left.5^{\circ}\right)$ as Instttuições Superiores de contrôle das finanças públicas devem estar aparelhadas para o exercicio de suas atribuiçốes, inclusive quanto à fiscalização da receita, com serviços mecanizados de contabilidade e estatistica.

Em referência aos métodos de apresentação orçamentária e contábıl que permitam avaliar o custo $\mathrm{c}$ a rentabilidade dos serviços públicos, foi reconhecido que o desenvolvimento das atribuições do Estado, especialmente as de ordem econômica e social, bem como o conseqüente aumento de despesas públicas, têm criado, na maior parte dos países, problemas novos, de natureza orçamentária e contábil. 
Assinalou ainda o "32 Congresso" que, - sem desprezar o principal objetivo de todo o sistema orçamentário e contábil (o de constituir uma prestação exata das contas do dispêndio regular dos créditos e assim assegurar o fiel cumprimento da vcntade das autoridades orçamentárias) -, impõe-se aconselhar que os documentos orçamentários e contábeis sejam vazados en forma tal que permitam destacar não só as diversas atividades do Estado, mas também os resultados obtidos como compensação dos sacrifícios financeiros que a Nação se císpôe a fazer.

Segundo essa premissa, o "3 Congresso" recomendou:

1\%) que, inspirando-se em a noção de orçamento funcional - ou seja de um orçamentc elaborado en função dos objetivos a atingir, e não apenas dos meios de execução --, os países interessados hão de proceder, no que lhes parecer possivel, a una revisão de sua nomenclatura orçamentária, e devem reagrupar os créditos segundo a natureza das atividades, sem que, para tanto, seja riecessário abandonar as normas tradicionais, referentes ao preparo, votação, execução e contrôle orçamentário;

$2^{\circ}$ ) que se estude e ponha em prática uma apresentação contábil que não apenas permita controlar o emprêgo dos créditos, mas também forneça informações quanto aos preços de custo e rendimento dos serviços. Não se ignoram as vantagens nem se desconhece também a complexidade das reformas a realizar nesse setor, se ido certo que se trata de tarefa demorada, cuja execução. forçosamente, terá de ser feita gradualmente; e

32) que as medidas a adotar deverão obedecer aos seguintes princípios :

a) nada diminuir das garantias necessárias a um contrôle preciso das operações orçamentárias;

b) ter o cuidado de evitar entraves às tarefas da Administração:

c) iniciar a reforma pelos setores que melhor se adaptem à aplicação dos novos métodos:

d) ter em consideração que a dificuldade de determinar, com precisão. para certis serviços, o custo e o rendimento de gestão, - isso não impede comparações proveitosas tanto para informação das autoridades orçamentárias quanto para o exercício da atividade controladora.

Finalmente, outro grande tema que ocupou a atenção do Plenário do "3. Congresso" foi c da fiscalização jurídico-financeira superior, na execução dos planos de desenvolvimento econômico e social.

A tal respeito, foi tornado patente que êsse problema tinha especial significação para as Instituições Superiores cuja atuação ainda se limita ao contrôle da legalidade, impedidas que estão, por isso, de apreciar as finalidades dos planos de desenvolvimento econômico e social e a sua economicidade.

Outra circunstància que importa ter em consideração, quando da feitura dos "Relatórios" ao Parlamento, - será a da posição das Entidades superiores de contrôle que sejam, ou não sejam, delegadas de órgão lagislativo. 
Essas Instituições de contrôle fazem, ou deverão fazer, apreciações sôbre os "planos" aprovados pelo própric Parlamento, e sôbre a execução que. foi dada a êsses mesmos "planos".

Daí, entre outras, as recomendaçôes do " 3 ? Congresso" sôbre a fiscalização jurídico-financeira superior, na execução de planos de desenvolvimento econômico e social:

$\left.1^{\circ}\right)$ às Instituiçōes superiorés de contrôle cuja atuação se limite ao exame de legalidade - não se lhes deve permitir pronunciamentos sôbre as finalidades ou sôbre a economicidade da planificação, devendo elas, no entanto, nos relatórios anuais ao Parlamento, expor suas observações com referência aos planos $e$ às faltas ou irregularidades verificadas na sua execução;

2.) entregue a execução dos «planosí a organizaçōes de interêsse público, -- as Instituiçõ $s$ superiores de contrôle sugerirão ao Parlamenı normas que prevejam fiscalização eficiente da gestão das ditas organizações, sempre que as vigentes leis aplicáveis năo forem satisfatórias.

Tais foram, em substância, as decisões do «3: Congresso Internacional das Instituições superiores de contrôle das finanças públicas", reunido em maio de 1959, na Cidade do Rio de Janeiro.

Estão, assim, resumidos os três Congressos Mundiais de Tribunais de Contas que terão seguimento com c: " 4 " Congresso Internacional das Instituições Superiores de contrôle das finanças públicas", a reunir-se, em 1962, em Viena, República Austríaca.

Fixada que está a matéria, logo que publicados os "Anais do $3^{\circ}$ Congresso" - passará a ser oportuno que se levante a conta de resultados, com o exame dos relatórios, das teses e da documentação, para as aquisições que devam ser incorporadas ao acervo doutrinário do campo especializado.

Por ora, fica, nas páginas da Revista do Serviço Público, êste breve roteiro que há de ser continuado, já então sob o ângulo da análise e da crítica construtiva. 